\title{
Study on Early Warning Service of Low-Temperature Chilling Injury Risk in Shenyang Facilities Agriculture
}

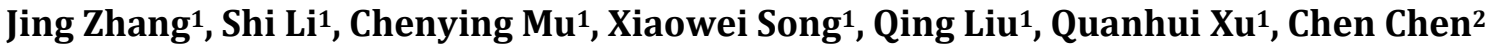 \\ ${ }^{1}$ Shenyang Meteorology Bureau, Shenyang, China \\ ${ }^{2}$ Qingyuan Manchu Autonomous County Meteorological Bureau, Qingyuan, China \\ Email:lnz00@126.com
}

How to cite this paper: Zhang, J., Li, S., $\mathrm{Mu}$, C.Y., Song, X.W., Liu, Q., Xu, Q.H. and Chen, C. (2018) Study on Early Warning Service of Low-Temperature Chilling Injury Risk in Shenyang Facilities Agriculture. Journal of Geoscience and Environment Protection, 6, 228-236.

https://doi.org/10.4236/gep.2018.65019

Received: January 19, 2018

Accepted: May 27, 2018

Published: May 30, 2018

Copyright $\odot 2018$ by authors and Scientific Research Publishing Inc. This work is licensed under the Creative Commons Attribution International License (CC BY 4.0).

http://creativecommons.org/licenses/by/4.0/

(C) (i) Open Access

\begin{abstract}
On the basis of summarizing the research on disaster risk at home and abroad, Shenyang, one of the cities with the most frequent meteorological disasters, was taken as an example. Cold chilling injury is one of the major agricultural meteorological disasters, which poses a serious threat to the sustainable development of agriculture and food security in Jilin and Shenyang. Based on meteorological observation data of recent 65 years in Shenyang and microclimate monitoring data of agricultural facilities in two years, this paper makes statistical analysis by mathematical statistics and calculates the highest outdoor temperature, the lowest indoor air temperature and the highest ceiling temperature according to the meteorological grade index of agricultural facilities' low temperature chilling damage, low temperature and other meteorological elements of grade indicators, analysis of greenhouse production trend of greenhouse climate change, and to discuss the relationship between temperature inside and outside the greenhouse and the facility microclimate conditions in agricultural cold weather disastrous and early warning services. The results showed that in the 21st century, the number of days with low temperature of $\leq-20^{\circ} \mathrm{C}$ increased significantly compared with those in the 1970s, 1980s and 1990s. The risk of low temperature chilling injury in facility agriculture in Shenyang was dominated by mild and moderate low temperature risk. Shenyang low temperature cold damage warning services standards to reduce the impact of chilling injury on agricultural facilities and development.
\end{abstract}

\section{Keywords}

Agricultural Facilities, Microclimate Observation, Low-Temperature Chilling Injury, Early Warning Service 


\section{Introduction}

China's research on chilling injury is only 40 years in history [1]. Abroad, Japan is a country where more cold and chilling damages are studied. Chilling injury is a major meteorological disaster in Japan's agricultural production. Historically, three major famines and multiple disasters during the Meiji period were caused by chilling injury. [2] Sasaki Chofu [3] analyzed the cold damage of rice in Hokkaido in 1980 and put forward the technical reasons for mitigating the cold damage, and gave some suggestions on the research on chilling damage and technical countermeasures. In other countries, there are many researches on the mechanisms of crop chilling injury. Among them, HG McPherson et al. [4] studied the effects of chilling injury on the growth of plant sprouts and the effect of Pierre Bertin [5]. The relationship between different contents of acid in plant solution was studied. Janda [6] [7] mainly studied the effects of chilling injury on photosynthesis. Foolad [8] and Lidon [9] mainly studied the mechanism of low temperature chilling injury on crops; Lukatkin [10] studied the changes of peroxide concentration in plant solution and thus the mechanism of plant chilling resistance. It can be seen that most foreign studies on chilling injury focus on the mechanism of chilling injury, while few studies on other aspects of chilling injury research, such as the risk warning of chilling injury.

The winter in Shenyang is long and cold. The sunshine and temperature in the solar greenhouse in winter can basically meet the needs of crop growth. The climate conditions are suitable for the development of facility agriculture. The farmers in facilities enjoy fewer profits and have more enthusiasms for planting. In recent years, the rapid development of facility agriculture has made great contributions to Shenyang area. City anti-seasonal vegetable supply provides a solid guarantee. The production of sunlight greenhouse is greatly influenced by the weather conditions. The strong and cold weather appearing in winter is one of the major meteorological disasters of anti-season vegetable production in our city, analyzing the occurrence rules of low-temperature weather, accurately forecasting its occurrence time and intensity, and making early warning service, which is of great importance to agricultural disaster prevention and mitigation in greenhouse facilities.

\section{Data and Methods}

\subsection{Data Sources}

The climate research data are from the conventional meteorological observation data of Shenyang National Basic Weather Station from 1951 to 2015. Using the average data of 30 years from 1981 to 2010 as the climatic analysis data, the extreme value information was extracted from the meteorological observation data of many years since meteorological observation.

The data of facility microclimate observation come from Shenyang Meteorological Bureau Microclimate Experimental Base. The observing site is the experiment booth of Academy of Agricultural Sciences of Dongling Road, Shenhe 
District, Shenyang. The observing equipment is the farmland microclimate automatic station of Jinzhou Sunshine Technology Company. The installation time of equipment is 2012 in June, the observational elements were greenhouse temperature, relative humidity, ground temperature, wet ground, ultrasonic wind direction, wind speed, total radiation, effective photosynthetic radiation and height 1.5 outside the shed.

\subsection{Establishment of Temperature Comparison and Prediction Model in and Outside Greenhouse}

Solar greenhouse greenhouse production period (October 2012 - April 2014). The average temperature in the greenhouse was $12.2^{\circ} \mathrm{C}, 15.2^{\circ} \mathrm{C}$ higher than the average outdoor observation temperature; the highest temperature in the greenhouse was $21.4^{\circ} \mathrm{C}$, which was higher than the highest temperature in the observation area $18.6^{\circ} \mathrm{C}$. The lowest temperature in the greenhouse was $7.5^{\circ} \mathrm{C}$ on average, $15.7^{\circ} \mathrm{C}$ higher than the minimum temperature in the observation field.

From the curve of the average temperature in shed, the maximum temperature in shed and the minimum temperature in greenhouse during the period of agricultural production, the change of shed temperature is directly affected by the outdoor temperature change with a slight lag. The outdoor temperature during the period of agricultural production. The change usually starts from October, gradually decreases, reaches the winter lowest value in January, then gradually increases as the seasonal climate picks up; Compared with the change of outdoor temperature, the change of temperature in greenhouse was obviously reduced. The temperature difference between indoor and outdoor was smaller in autumn, and the temperature difference between indoor and outdoor in winter was larger. The temperature difference between indoor and outdoor was gradually reduced in spring. The change of the highest temperature inside and outside the greenhouse reached the maximum temperature difference in December. The maximum temperature difference between inside and outside the greenhouse was $25.1^{\circ} \mathrm{C}$. The average temperature inside and outside the greenhouse reached the maximum temperature difference in January. The average temperature difference in the month was $21.6^{\circ} \mathrm{C}$ and $24.0^{\circ} \mathrm{C}$ (Figure 1). Based on the contrast observation data inside and outside the microclimate station, through the classification of different seasons and different types of weather, a stepwise regression method was used to establish the model of temperature forecast in the greenhouse. The division of weather type is divided by day average total cloud amount: $0 \leq$ cloud amount $<2$, sunny day; $2 \leq$ cloud amount $\leq 8$ is cloud day (less cloud, cloudy); $8<$ Cloudiness $\leq 10$ is cloudy. Based on the data of greenhouse microclimate from October 2012 to April 2013, a simulation model of air temperature in greenhouse was established, and the forecast model was tested by using data from October 2013 to April 2014. Six types of forecasting models (Table 1) were established according to the three weather types of sunny day, cloudy day and overcast day, and different seasons in winter and spring/autumn. 


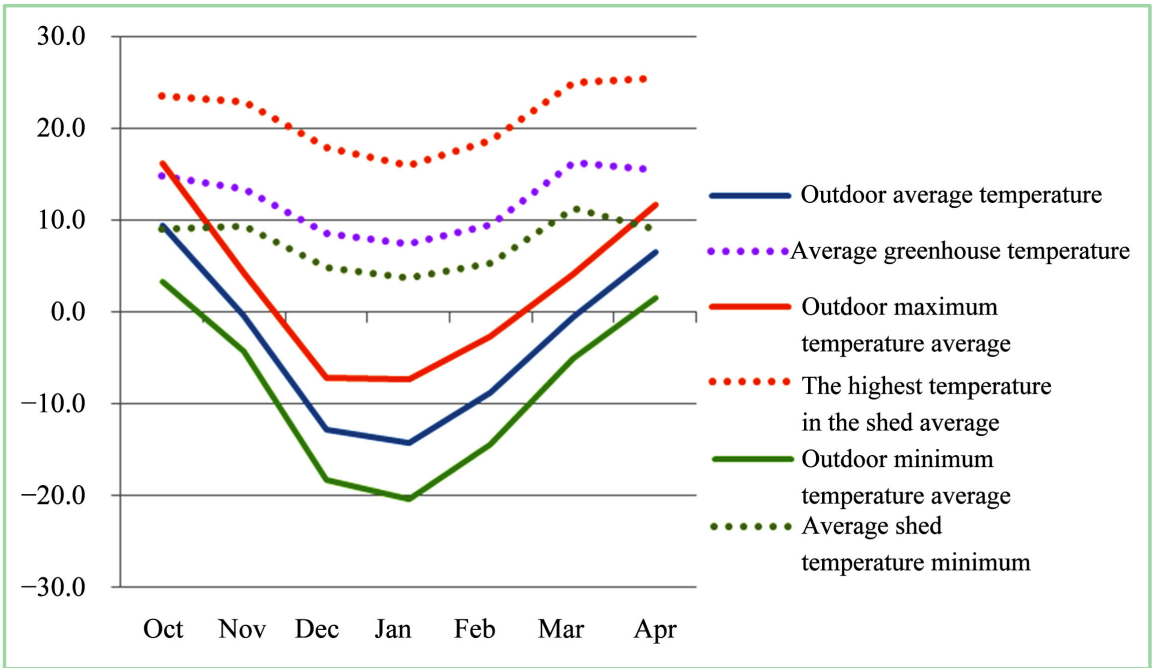

Figure 1. Facilities during agricultural production greenhouse temperature and outdoor temperature contrast.

Table 1. Different weather types shed minimum temperature forecast model.

\begin{tabular}{|c|c|c|c|c|}
\hline $\begin{array}{l}\text { Weather } \\
\text { type }\end{array}$ & $\begin{array}{l}\text { Number of } \\
\text { samples }\end{array}$ & Temperature simulation equation & $\begin{array}{l}\text { Number of } \\
\text { test samples } \\
\text { (pieces) }\end{array}$ & $\begin{array}{l}\text { Forecast, } \\
\text { measured } \\
\text { difference } \\
\quad\left({ }^{\circ} \mathrm{C}\right)\end{array}$ \\
\hline Sunny day & 59 & $\begin{array}{l}\text { Autumn } \backslash \text { Spring: } \mathrm{Y}=0.459 \mathrm{X}_{\text {The lowest day before the }} \\
\text { shed }+0.115 \mathrm{X} \text { The highest ceiling in the previous day }+0.250 \\
\text { Winter: } \mathrm{Y}=0.255 \mathrm{X}_{\text {The lowest day before the shed }}+ \\
0.093 \mathrm{X}_{\text {The highest ceiling in the previous day }}+0.711\end{array}$ & 13 & 3.2 \\
\hline $\begin{array}{l}\text { partly } \\
\text { cloudy }\end{array}$ & 117 & $\begin{array}{l}\text { Autumn } \backslash \text { Spring: } \mathrm{Y}=0.522 \mathrm{X}_{\text {The lowest day before the }} \\
\text { shed }+2.265 \\
\text { Winter: } \mathrm{Y}=0.104 \mathrm{X}_{\text {Outdoorminimum temperature }}+ \\
0.447 \mathrm{X}_{\text {The lowest day before the shed }}+0.107 \mathrm{X}_{\text {The highest }} \\
\text { ceiling in the previous day } \\
+2.244\end{array}$ & 33 & 1.3 \\
\hline cloudy day & 36 & $\begin{array}{l}\text { Autumn } \backslash \text { Spring: } \mathrm{Y}=0.321 \mathrm{X}_{\text {Outdoor minimum }} \\
\text { temperature }+9.404 \\
\text { Winter: } \mathrm{Y}=0.25 \mathrm{X}_{\text {Outdoor minimum temperature }}+ \\
10.698\end{array}$ & 15 & -1.4 \\
\hline
\end{tabular}

\section{Low Temperature Chilling Risk Analysis and Early Warning Services}

\subsection{Risk Analysis of Facility Agricultural Chilling Injury}

The change curves of the days with low temperature in winter from $-20^{\circ} \mathrm{C}$ to $20^{\circ} \mathrm{C}$ in 1951-2015 show that the days of low temperature in $\leq 65^{\circ} \mathrm{C} \leq 20^{\circ} \mathrm{C}$ in our city show the trend of "increase-decrease-increase", the overall linear trend rate is -0.558 days/10a, 20 In the 1950s and 1960s, the period of high temperature with low temperature began to decrease at the beginning of the 1960s and the beginning of the 1970s. However, the number of low temperature days with $\leq-20^{\circ} \mathrm{C}$ in the 21 st century increased significantly from the 1970 s, 1980s and 
1990s. The average number of days with the lowest day temperature below $-20^{\circ} \mathrm{C}$ in winter in recent 62 years was 14 days, the year with the highest number of low temperature days in winter occurred in 1956, the number of days with low temperature below $20^{\circ} \mathrm{C}$ was 60 days, the lowest number of days with low temperature in $\leq-20^{\circ} \mathrm{C}$ in 1987 , Only one day (see Figure 2). In recent years, the city has obviously increased the number of days of low-temperature disastrous weather, adversely affecting the production of facilities and agriculture in our city. Chilling injury in winter is one of the major disasters that affect the agricultural production of facilities in our city. Based on the observation and comparison of temperature inside and outside greenhouse, based on previous observations and studies [11] [12] [13], reference is made to the classification of chilling injury indicators in different areas to determine the $\mathrm{Td} \geq-26$ and $-22<\mathrm{Td}$ $\leq-26,-20<\mathrm{Td} \leq-22$, respectively, for the severity, moderate and mild degree of chilling injury indicators. According to the survey, mild low-temperature chilling can affect or delay the normal growth of greenhouse tomatoes. Moderate low-temperature chilling injury can cause chilling (or disease) in greenhouse tomatoes, and cold (severe) chilling injury can cause death Two years Xinmin, Dongling two facilities agricultural shed artificial observation records as supporting information).

Through the identified indicators of chilling injury temperature, we conducted statistics on the frequency of chilling injury risks at different levels during the agricultural production period of Shenyang facility. From the monthly frequency analysis of chilling injury risk, the months with the highest risk of chilling injury in our city are January and December And in February, the risk of chilling in early spring and autumn is almost 0 (Table 2).

Statistics of nearly 30 years of climatological data, the average risk of cold damage during agricultural production in our city was 14 days/year, of which the severity of risk, moderate and mild degree of chilling risk days were 1.4 days, 6.4 days and 6.2 days, respectively, with light Degree and moderate degree of chilling risk, and the days of chilling risk in the past three years since the beginning of the decade of the 21st century increased significantly to 33 days, 27 days and 24 days, respectively, and entered the high risk period of agricultural chilling injury in winter facilities. The average of the past five years Chilling injury risk days was 21.2 days (see Table 3 ).

\subsection{Facilities Agricultural Warning Service}

The existing facilities crop weather disaster early warning mainly includes the following two ways: 1) An alarm is issued based on real-time observation data and disaster indicators to determine if they meet the disaster criteria. 2) With the support of real-time monitoring data, combined with the weather forecast results of local meteorological stations, early warning of low-temperature disasters is carried out [14]. Both of these two methods require real-time monitoring of microclimate in the greenhouse. In actual production practice, greenhouse gas 


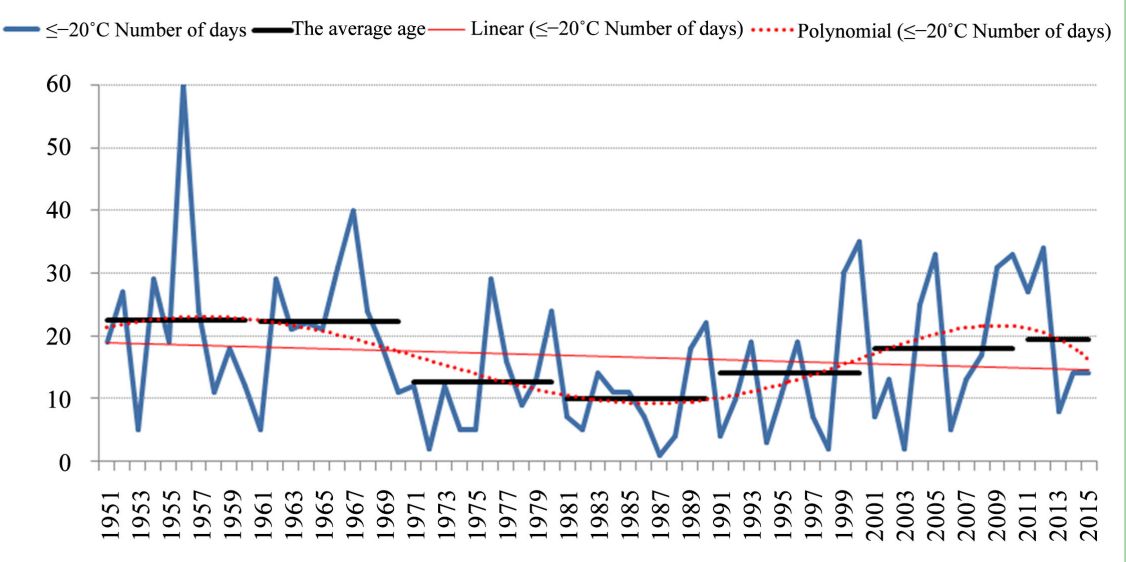

Figure 2. Winter $\leq-20^{\circ} \mathrm{C}$ low temperature days curve.

Table 2. Shenyang facilities in different stages of agricultural production chilling hazard frequency statistics (times/year).

\begin{tabular}{ccccc}
\hline month & severity & intermediate & Lighter & $\begin{array}{c}\text { The total number of chilling damage at } \\
\text { all levels }\end{array}$ \\
\hline October & 0 & 0 & 0 & 0 \\
November & 0 & 0 & 0.1 & 0.1 \\
December & 0.2 & 1.4 & 1.4 & 3.0 \\
January & 1.0 & 4.1 & 3.6 & 8.7 \\
February & 0.2 & 0.8 & 1.0 & 2.0 \\
March & 0 & 0 & 0 & 0 \\
April & 0 & 0 & 0 & 0 \\
\hline
\end{tabular}

Table 3. Facilities agricultural production at all levels of chilling injury risk days to determine.

\begin{tabular}{|c|c|c|c|c|}
\hline & $\begin{array}{c}\text { severity } \\
\text { Chilling risk } \\
\text { days }\end{array}$ & $\begin{array}{c}\text { intermediate } \\
\text { Chilling risk days }\end{array}$ & $\begin{array}{c}\text { Mild degree } \\
\text { Chilling risk days }\end{array}$ & $\begin{array}{c}\text { Chilling risk } \\
\text { days total }\end{array}$ \\
\hline$\star 30$ year average & 1.4 & 6.4 & 6.2 & 14 \\
\hline 2010-2011 & 8 & 19 & 6 & 33 \\
\hline 2011-2012 & 1 & 8 & 18 & 27 \\
\hline $2012-2013$ & 7 & 18 & 9 & 24 \\
\hline 2013-2014 & 0 & 2 & 6 & 8 \\
\hline 2014-2015 & 0 & 6 & 8 & 14 \\
\hline Nearly 5 years average & 3.2 & 10.6 & 9.4 & 21.2 \\
\hline
\end{tabular}

*30-year average for the 1981-2010 climate averages.

microclimate observation equipment can not be set up within the shed for each agricultural production user in the facility. Therefore, the facility agriculture based on the above method Disaster early warning is not easy to promote. 
Compared to the greenhouse microclimate observations, conventional meteorological elements are more readily available. The key to solving this problem lies in establishing the relation model of meteorological elements inside and outside the greenhouse for different greenhouse structures. Combining with the measured data of the experimental shed and the analysis of crop disaster information, the critical values of the meteorological elements inside and outside the greenhouse are obtained. Light, medium and heavy different degrees to define the critical index of the temperature elements of low temperature disasters and establish early warning service standards for outdoor low temperature forecast so as to achieve the purpose of using the conventional meteorological elements forecast information for greenhouse disaster early warning services and to launch timely and effective warning service. The establishment of agricultural facilities in Shenyang low temperature chills early warning service standards are as follows:

1) It is predicted that the daily minimum temperature $<-22^{\circ} \mathrm{C}$ will appear on the next day in individual counties, indicating that the range of cold air activities is small and the impact is slight. No special warning information may be issued and the service is in normal working mode.

2) When there are two or more county minimums $<-2 \mathrm{O}<0>\mathrm{C}$ on the next day of forecast, and extreme temperatures can reach below -24 degrees Celsius, there will be medium-level facilities agricultural chilling injury and low temperature warning and facility agricultural warning should be issued.

3) When the daily minimum temperature of $<-24^{\circ} \mathrm{C}$ appears in more than two counties on the next day and the extreme temperature reaches below $-26^{\circ} \mathrm{C}$, an emergency warning of facility agricultural emergencies will be issued and a report on the special reports will be sent to the municipal competent leaders. In conjunction with the Joint Commission of Agriculture and Economic Cooperation, Facilities agricultural cold damage prevention, to the county meteorological departments to implement 24-hour dynamic tracking service.

Through the collection of experience and suggestions from agricultural experts and production users, we can obtain more disaster early warning and defensive measures and give some early warnings such as water control, smoked, curtains and additional sheds and other supplementary warming warnings in the early warning service Service defensive measures.

\subsection{Service Case}

December 27, 2013 Municipal Meteorological Bureau released agricultural service materials for facilities "Snow precipitation cooling weather facilities agriculture needs to be strengthened on 28 - 30 days", the summary is as follows:

[Abstract] From January 28 to 29, there will be a local heavy snowfall in the city. The snowfall will be $3-5 \mathrm{~mm}$. The urban area, Dongling, Sujiatun and Shenbei snowfall may be larger and may reach or exceed $5 \mathrm{~mm}$. After the snow 
temperature dropped significantly, the minimum temperature on the 30 th than the minimum temperature on the 29 th down $10^{\circ} \mathrm{C}-12^{\circ} \mathrm{C}$. It is suggested to timely clean the snow on the greenhouse, reinforce the scaffolding facilities, prevent the collapse of the scaffolding or increase the frost damage by the wind blowing up the membrane, and do a good job of cold preservation and temperature and humidity control in the shed interior.

\section{Conclusion and Discussion}

1) The change of temperature inside the shed is directly affected by the change of outdoor temperature, with a certain lag. The maximum temperature inside and outside the shed reaches the maximum temperature difference in December, with an average temperature difference of $25.1^{\circ} \mathrm{C}$. The average temperature inside and outside the shed reaches the maximum temperature difference in January, The average monthly temperature differences were $21.6^{\circ} \mathrm{C}$ and $24.0^{\circ} \mathrm{C}$.

2) Mathematical and statistical methods were used to compare six kinds of greenhouse minimum temperature forecast models by using different observational data of microclimate stations and dividing different seasons and different weather types.

3 ) In the 21 st century, the number of low-temperature days of $\leq-20^{\circ} \mathrm{C}$ is obviously higher than that of the 1970s, 1980s and 1990s. The risk of low-temperature chilling injury in winter agricultural facilities in Shenyang is mainly mild and moderately low temperature.

4) According to the index of risk of cold damage, the service standard of low temperature and chilling injury forecast and warning in our city is determined. When the daily minimum temperature $<-24^{\circ} \mathrm{C}$ appears in more than 2 counties on the next day and the extreme temperature reaches below $-26^{\circ} \mathrm{C}$, and triggers the highest level of low temperature warnings.

5) Through the research on early warning of multiple chilling hazards, the research and application of accurate fertilization technology to prevent chilling injury will be strengthened, and the research and application of chemical control technology to resist chilling damage will be intensified. The research results in these fields will exert a multiplier effect on the defense against chilling injury.

\section{Funding}

This work was funded by Shenyang City Science and Technology Plan Project (F14-113-3-00) "Survey of Agricultural Meteorological Disaster Monitoring and Assessment Technology in Shenyang" and China Meteorological Administration Public Welfare Industry (Meteorology) Research Project (GYHY201206024) "Research on Weather Forecast Technology of Facility Agricultural Production in Northeast China". 


\section{References}

[1] Wang S.Y. (1984) China Crop Chilling Research Progress. Meteorological Science and Technology, 4, 75-79.

[2] Okuta, M. (1957) Chilling Japan: Cruel Realities and Countermeasures. Tokyo: Toyo Keizai Net.

[3] Toshio, S. (1981) Chilling Injury in Hokkaido in 1980 and Its Technical Requirements. Journal of Yanbian Agricultural College, 3, 33-43.

[4] Mcpherson, H.G., Manson, P.J. and Snelgar, Q.P. (1997) Non-Destructive Measurement of Dormant Bud Respiration Rates. Photosyn-Thetica, 33, 125-138. https://doi.org/10.1023/A:1022187524539

[5] Bertin, P., Bullens, P., Bouharmont, J., et al. (1998) Somaclonal Variation and chilling Tolerance Improvement in Rice: Changes in Fatty Acid Composition. Plant Growth Regulation, 24, 31-41. https://doi.org/10.1023/A:1005950113741

[6] Janda, T., Szalai, G., Ducruet, J.M., et al. (1998) Changes in Photosyn-Thesis in Inbred Maize Lines with Different Degrees of Chilling Tolerance Grown at Optimum and Suboptimum Temperatures. Photosynthetica, 35, 205-212.

https://doi.org/10.1023/A:1006954605631

[7] Janda, T., Szalai, G. and Paldi, E. (2000) Thermoluminescence Investigation of Low Temperature Stress in Maize. Photosynthetica, 38, 635-639. https://doi.org/10.1023/A:1012477911191

[8] Foolad, M.R. and Lin, G.Y. (2001) Genetic Analysis of Cold Tolerance during Vegetative Growth in Tomato, Lycopersicon esculentum Mill. Euphytica, 122, 105-111. https://doi.org/10.1023/A:1012616231637

[9] Lidon, F.C., Loureiro, A.S., Vieira, D.E., et al. (2001) Photoinhibition in Chilling Stressed Wheat and Maize. Photosynthetica, 39, 161-166. https://doi.org/10.1023/A:1013726303948

[10] Lukatkin, A.S. (2002) Contribution of Oxidative Stress to Development od Cold-Induced Damage on Leaves of Chilling-Sensitive Plants: 1.Reactive oxygen Species Formation during Plant during Plant Chilling. Russian Journal of Plant Physiology, 49, 622-627. https://doi.org/10.1023/A:1020232700648

[11] Li, M.R., Li, H.L., Bai Q.F., et al. (2010) Calculation of Vegetable Chilling Hazard and Its Warming Type Based on County Unit in Sunlight Greenhouse of China. Chinese Agricultural Science Bulletin, 26, 318-324.

[12] Sun, Z.H., Li, H.Q., Zheng, X.Y., et al. (2005) Analysis and Forecast of Winter Chilling Injury in Sunlight Greenhouse in Yanan. China Agricultural Meteorology, 26, 197-199.

[13] Sun, Z.H. (2004) Effect of Winter Severe Cold Weather on Crops in Solar Greenhouse. Meteorological Science and Technology, 32, 126-128.

[14] Chen, S.N., Li, Z.F., Liu, S.M., et al. (2014) Overview of Research on Agricultural Meteorological Disasters and Prospect of Research Methods. Chinese Agricultural Science Bulletin, 30, 302-307. 